\title{
Factors Associated with the Walking Ability of Hemiplegic Stroke Patients
}

\author{
Akira Matsuyama \\ Department of Nursing, School of Health Sciences, Toyohashi Sozo University, Aichi, Japan \\ Email: a-matsuyama@sozo.ac.jp
}

How to cite this paper: Matsuyama, A. (2018) Factors Associated with the Walking Ability of Hemiplegic Stroke Patients. Open Journal of Nursing, 8, 14-25. https://doi.org/10.4236/ojn.2018.81002

Received: December 12, 2017

Accepted: January 21, 2018

Published: January 24, 2018

Copyright $\odot 2018$ by author and Scientific Research Publishing Inc. This work is licensed under the Creative Commons Attribution International License (CC BY 4.0).

http://creativecommons.org/licenses/by/4.0/

\begin{abstract}
Gait disturbance due to motor paralysis affects activities of daily living and quality of life in patients with stroke. Thus, commencing walking training from the acute phase of recovery is essential. This study aimed to clarify the factors affecting the walking ability of hemiplegic stroke patients. Eighty hospitalized patients with a first chemic or hemorrhagic stroke within 1 year but not less than 1 month after stroke onset were included in this study. The dependent variable was walking ability (Functional Independence Measure [FIM] locomotion score), and the independent variables were spirituality (Spirituality Rating Scale-A [SRS-A]), amount of social support (Japanese version of the Abbreviated Multidimensional Scale of Perceived Social Support, frequency of family visit), stroke severity (National Institutes of Health Stroke Scale [NIHSS]), degree of motor paralysis (lower extremity Brunnstrom stage), the lower limb loading force of the affected and unaffected side, and age. Spearman's rank correlation coefficient and multiple regression analysis were performed. Multiple regression analysis showed that FIM locomotion score was associated with NIHSS (standard partial regression coefficient $=$ $-0.362, P<0.001$ ), the unaffected lower limb loading force (standard partial regression coefficient $=0.264, P<0.001$ ), lower extremity Brunnstrom stage (standard partial regression coefficient $=0.352, P<0.001$ ), and SRS-A (standard partial regression coefficient $=0.184, P<0.011$ ). From our findings, walking ability was affected by stroke severity and the degree of paralysis, the unaffected lower limb loading force, and the spirituality level in patients with stroke. Promoting walking ability in patients with stroke includes training the unaffected lower limb and heightening spirituality. Training of the unaffected lower limb should be performed at the bedside or on the bed by the patient or a bedside nurse. To heighten spirituality, nurses who care for patients with stroke are encouraged to practice active listening and to show sympathy as part of emotional support and spiritual care.
\end{abstract}




\section{Keywords}

Stroke, Gait, Paralysis, Muscle, Spirituality

\section{Introduction}

Hemiplegic stroke patients often experience gait disturbance, such as spastic gait, due to motor paralysis. Gait disturbance affects activities of daily living (ADL) and the quality of life of patients [1] [2]. Thus, early walking training is essential.

Motor paralysis, one of the neurologic manifestations of stroke, is caused by an upper motor neuron lesion and causes muscle coordination impairment because of muscle contraction imbalance; moreover, muscular strength is decreased by reduced maximal voluntary force [3]. Consequently, patients with stroke are unable to load the affected limb, affecting walking ability; lower limb loading force contributes to walking ability.

Psychosocial and spiritual factors are also essential to the walking ability of hemiplegic stroke patients. Social support influences mental health conditions [4], and a high level of social support from family members improves the functional status, and thus, the mental health of patients with stroke [5]. Spirituality is considered to be the essence of one's being and gives meaning and purpose to our existence [6]. An individual, as a whole, is the integration of body, mind, and spirit [7]. Thus, heightened spirituality enhances the physical and mental status of the patients. Since social support and spirituality affect patients' mental condition, assessing and enhancing social support and spirituality, as well as motivation in these patients are necessary to aid the recovery of walking ability. In the early rehabilitation of patients with acute stroke, it is reported that shorter, more frequent mobilization results in favorable outcomes and walking by 3 months, with a decrease in mortality rate and complications [8]. Thus, assisting these patients with rehabilitation from an early stage in the ward is necessary to accelerate recovery.

Moreover, patients with stroke are at risk for falls due to impaired motor functions, and emotional and cognitive factors are thought to play a role. Experiencing a fall results in the "fear of falling" [9], which is defined as "a lasting concern about falling that leads to an individual avoiding activities". "Fear of falling", thus, affects the patients' quality of life and results in physical and psychological symptoms, such as anxiety [10] [11]. Preventing falls at the initial stage of walking training is vital, and requires the accurate assessment of healthcare professionals on the patient's physical and psychosocial conditions.

Nurses are responsible for the assessment of the patient's readiness, including physical and psychosocial conditions, when starting walking training because nurses perform around-the-clock patient observation and are in the best position to notice subtle changes in the patients' condition. Knowledge about the factors influencing walking ability could help nurses perform anaccurate assess- 
ment of the patients in the acute phase of recovery. Although the relationship between walking ability and physical status has been studied, psychosocial and spiritual factors and their effect on walking ability have not been widely investigated. Thus, the purpose of this study was to clarify the factors, including psychosocial and spiritual factors, affecting the walking ability of hemiplegic stroke patients.

\section{Methods}

\subsection{Subjects}

Hemiplegic patients with stroke who had their first ischemic or hemorrhagic stroke,based on a doctor's diagnosis, within 1 year but not less than 1 month after stroke onset and who were admitted in two hospitals in Aichi and Ibaraki prefectures in Japan were screened for their eligibility to participate in this study. Data were collected from December 2013 to March 2016. Patients using a wheelchair or mobility aids and undergoing training in the rehabilitation room were included. The patients' cognitive function was also assessed and those with $\geq 21$ points in the revised Hasegawa's Dementia Scale were included in the study. Those who had difficulties following an instruction because of a neuropsychological deficit or mental confusion were excluded. In this study, in consideration of the burden on the subjects and safety, we targeted patients with stroke after acute care. The total sample size was 80 , which well exceeds the sample size calculated with a large effect size $\left(f^{2}=0.35\right)$ [12].

\subsection{Instruments}

In this study, the dependent variable was walking ability and the independent variables were spirituality, amount of social support, stroke severity, degree of motor paralysis, lower limb loading force, and age.

Walking ability was determined by the Functional Independence Measure (FIM) locomotion score [13]. FIM consists of 13 motor items and 5 cognitive items. Each item ranges from 1 to $7(1=$ total assistance, $7=$ complete independence) [13].

Spirituality was measured by SRS-A, which was developed by Higa. SRS-A is a 15-item 5-point scale that includes a no-religion item and is unaffected by disease, sex, or age [14]. The highest SRS-A score is 75 points, and the results are categorized as follows: $\leq 29$ points = very low, $30-39$ points $=$ low, $40-49$ points $=$ moderate, $50-59$ points $=$ high, and $60-75$ points $=$ very high [15]. Social support was measured by the Japanese version of the Abbreviated Multidimensional Scale of Perceived Social Support [16] and the frequency of family visits within 30 days from the measurement date. The Japanese version of the Abbreviated Multidimensional Scale of Perceived Social Support is a 7-item 7-point scale based on the results of the factor analysis of the Japanese version of the Multidimensional Scale of Perceived Social Support. The maximum score is 49 points and a higher score indicates higher perceived social support [16]. In a 
previous study that measured social support by the frequency of family visits, frequency of family visits was reported to be associated with mortality in patients with large burns [17]. In addition, a high level of social support from family members has been reported to improve the functional status and mental health conditions of patients with stroke [5]. Therefore, we used the frequency of family visits as a measure of social support in this research [17].

Stroke severity was assessed by the National Institutes of Health Stroke Scale (NIHSS) [18] and the degree of motor paralysis was determined by the lower extremity Brunnstrom stage [19].

The lower limb loading force was measured by a forceful step on a commercial bathroom scale [20]. A commercial bathroom scale is inexpensive and requires no particular training; thus, measurement at the bedside is easy. Moreover, an objective assessment is possible with numerical values.

\subsection{Data Collection}

A floor nurse or a rehabilitation department head informally obtained the consent of the subjects who met the inclusion criteria to receive information regarding the study. The researcher explained the purpose, procedure, and ethical considerations; 82 patients were approached and two refused to participate. A signed informed consent was obtained from the 80 patients who were willing to participate. Thereafter, the subjects filled out the SRS-A andthe Japanese version of the Abbreviated Multidimensional Scale of Perceived Social Support. On the same day, depending on the patients' convenience, the researcher assessed the stroke severity, lower extremity Brunnstrom stage, lower limb loading force of both sides, and walking ability. Information about the frequency of family visits, age, height, weight, sex, and stroke profiles was obtained from medical records.

The lower limb loading force was measured as follows: the subject sat at the edge of a bed $45 \mathrm{~cm}$ high and $8 \mathrm{~cm}$ from the patient's popliteal region. The subjects stepped their right or left sole on a bathroom scale (HD-654, TANITA) and forced the sole down vertically with a maximum effort for $30-$ s. The subjects were free to take any posture, without lifting their buttocks from the bed, such that the movements in the sagittal plane and frontal plane of the trunk were not limited [20]. The measurement was performed twice for each limb. A 30-s interval was allowed between each measurement. The maximum value of each limb denotes the lower limb loading force $(\mathrm{kg})$, which was converted to body weight ratio percentage (\%). NIHSS, the lower extremity Brunnstrom stage, and FIM locomotion score were measured following their manuals.

This study was approved by Ethics Committee of Nagoya University Graduate School of Medicine (approval number 13 - 151).

\subsection{Reliability and Validity}

The reliability of self-report scales was determined by internal consistencies. Cronbach's alpha coefficients were 0.82 [14] and 0.85 [16] in previous studies and 0.811 and 0.898 in this study for SRS-A and the Japanese version of the Ab- 
breviated Multidimensional Scale of Perceived Social Support, respectively.

Reliability of lower limb loading force data was assured at each measurement through bathroom scale calibration by placing a $5-\mathrm{kg}$ weight after confirming zero display. Zero display was reconfirmed after removing the weight. The intra-class correlation coefficient of the lower limb loading force was reported as 0.823 [20]; in this study, it was 0.905 .

All measurements were performed by a single researcher who holds a master's degree in physical therapy.

\subsection{Data Analysis and Statistics}

Spearman's rank correlation coefficient between variables and multiple regression analysis with stepwise procedure were performed. The dependent variable was FIM locomotion score, and the independent variables were SRS-A, the Japanese version of the Abbreviated Multidimensional Scale of Perceived Social Support, frequency of family visit, NIHSS, the lower extremity Brunnstrom stage, the lower limb loading force of the affected and unaffected side, and age. The statistical analysis was performed using IBM SPSS ver.23 statistical software. A $P$-value $<0.05$ was considered statistically significant.

This study was approved by Ethics Committee of Nagoya University Graduate School of Medicine (approval number 13 - 151).

\section{Results}

The patients' demographic characteristics are shown in Table 1. Spearman's rank correlation coefficients of the variables are presented in Table 2. FIM locomotion score correlated with the lower extremity Brunnstrom stage $(\mathrm{r}=0.731$, $P<0.001)$, lower limb loading force of the affected and unaffected side $(\mathrm{r}=0.694$, $P<0.001$ and $\mathrm{r}=0.529, P<0.001$, respectively), and NIHSS $(\mathrm{r}=-0.634, P<$ 0.001). SRS-A correlated with the Japanese version of the Abbreviated Multidimensional Scale of Perceived Social Support $(\mathrm{r}=0.478, P<0.001)$.

Multiple regression analysis showed that FIM locomotion score was related to NIHSS (standard partial regression coefficient $=-0.362, P<0.001$ ), the unaffected lower limb loading force (standard partial regression coefficient $=0.264, P$ $<0.001$ ), the lower extremity Brunnstrom stage (standard partial regression coefficient $=0.352, P<0.001$ ), and SRS-A (standard partial regression coefficient $=0.184, P<0.011)$. The analysis of variance result was statistically significant $(P$ $<0.001)$. The total adjusted $\mathrm{R}^{2}$ of the variables was 0.61 , and the variance inflation factor was $1.864,1.150,1.851$, and 1.019 , respectively. No multicollinearity problem was observed (Table 3).

\section{Discussion}

This study revealed an association between FIM locomotion score and NIHSS, the unaffected lower limb loading force, the lower extremity Brunnstrom stage, and SRS-A based on the multiple regression analysis results. 
Table 1. Participant characteristics $(\mathrm{N}=80)$.

\begin{tabular}{|c|c|c|}
\hline Characteristics & $\mathrm{N}(\%)$ & Range \\
\hline \multicolumn{3}{|l|}{ Sex } \\
\hline Male & $46(58 \%)$ & \\
\hline Female & $34(42 \%)$ & \\
\hline Age (year; mean $\pm S D$ ) & $70.79 \pm 10.46$ & $47-88$ \\
\hline \multicolumn{3}{|l|}{ Disease type of stroke } \\
\hline Cerebral infarction & $46(58 \%)$ & \\
\hline Cerebral hemorrhage & $34(42 \%)$ & \\
\hline \multicolumn{3}{|l|}{ Hemiplegic side } \\
\hline Right hemiplegic & $28(35 \%)$ & \\
\hline Left hemiplegic & $52(65 \%)$ & \\
\hline Body mass index $\left(\mathrm{kg} / \mathrm{m}^{2} ; M \pm S D\right)$ & $22.13 \pm 3.66$ & $13.87-31.96$ \\
\hline FIM locomotion score & $5 \pm 1.86$ & $1-7$ \\
\hline Independent gait & $28(35 \%)$ & \\
\hline Use of wheelchair & $31(39 \%)$ & \\
\hline Use of mobility aid & $21(26 \%)$ & \\
\hline SRS-A & $45.28 \pm 12.22$ & $20-75$ \\
\hline The Japanese version of the Abbreviated Multidimensional Scale of Perceived Social Support & $37.5 \pm 8.74$ & $10-49$ \\
\hline Family visit per 30 days & $16.08 \pm 12.25$ & $0-30$ \\
\hline NIHSS & $2.36 \pm 2.73$ & $0-11$ \\
\hline The lower extremity Brunnstrom stage & $4.92 \pm 1.41$ & $1-6$ \\
\hline \multicolumn{3}{|l|}{ The lower limb loading force } \\
\hline Affected side & $23.11 \% \pm 10.03 \%$ & $3-53$ \\
\hline Unaffected side & $28.42 \% \pm 8.87 \%$ & $8-46$ \\
\hline
\end{tabular}

Table 2. Spearman's rank correlation coefficients between variables.

\begin{tabular}{|c|c|c|c|c|c|c|c|c|c|}
\hline & FIM & SRS-A & JAMSPSS & $\begin{array}{l}\text { Family visit } \\
\text { per } 30 \text { days }\end{array}$ & NIHSS & Brunnstrom stage & LLLF affected side & LLLF unaffected side & Age \\
\hline FIM & 1.000 & & & & & & & & \\
\hline SRS-A & 0.079 & 1.000 & & & & & & & \\
\hline JAMSPSS & 0.113 & $0.478^{* *}$ & 1.000 & & & & & & \\
\hline $\begin{array}{l}\text { Family visit } \\
\text { per } 30 \text { days }\end{array}$ & -0.015 & $0.384^{* *}$ & $0.486^{* *}$ & 1.000 & & & & & \\
\hline NIHSS & $-0.634^{* *}$ & 0.087 & -0.068 & 0.013 & 1.000 & & & & \\
\hline Brunnstrom stage & $0.713^{* *}$ & -0.119 & 0.034 & -0.146 & $-0.616^{* *}$ & 1.000 & & & \\
\hline LLLF affected side & $0.694^{* *}$ & 0.008 & -0.015 & -0.070 & $-0.697^{* *}$ & $0.552^{* *}$ & 1.000 & & \\
\hline LLLF unaffected side & $0.529^{* *}$ & -0.042 & -0.100 & -0.122 & $-0.416^{* *}$ & $0.349^{* *}$ & $0.745^{* *}$ & 1.000 & \\
\hline Age & -0.178 & 0.023 & 0.045 & -0.036 & -0.110 & -0.132 & -0.008 & -0.203 & 1.000 \\
\hline
\end{tabular}

Note. FIM = Functional Independence Measure; SRS-A = Spirituality Rating Scale-A; JAMSPSS = Japanese version of the Abbreviated Multidimensional Scale of Perceived Social Support; NIHSS $=$ National Institutes of Health Stroke Scale; LLLF $=$ lower limb loading force ${ }^{* *} p<0.05$.

\subsection{The Role of the Unaffected Lower Limb}

Walking ability is related to the degree of motor paralysis of the affected side. This finding is consistent with previous studies [21]. In contrast, walking ability is not related to the lower limb loading force of the affected side but is related to 
Table 3. Multiple regression analysis of the results between the locomotion score of FIM and independent variables $(\mathrm{N}=80)$.

\begin{tabular}{ccccc}
\hline Independent Variables & Coefficient & $\beta$ & $p$ & VIF \\
\hline NIHSS & -0.246 & -0.362 & $<0.001$ & 1.861 \\
Unaffected lower limb loading force & 0.056 & 0.264 & 0.001 & 1.148 \\
Brunnstrom stage & 0.465 & 0.352 & $<0.001$ & 1.849 \\
SRS-A & 0.028 & 0.184 & 0.011 & 1.009 \\
\hline
\end{tabular}

Note. FIM = Functional Independence Measure; VIF = Variance Inflation Factor; NIHSS = National Institutes of Health Stroke Scale; SRS-A = Spirituality Rating Scale-A; ANOVA $p<0.001$; Adjusted $\mathrm{R}^{2}=0.61$.

that of the unaffected side. This could be due to the gait characteristics of patients with stroke. Bohannon reported that there are patients who do not load the lower limb of the affected side while walking, based on electromyography [22]. Furthermore, in patients with stroke, the stance phase of the affected side is longer than that of the unaffected side in the gait cycle [23]. When the patients cannot load the affected lower limb, the support duration by the affected lower limb becomes shorter and support durations by both lower limbs and by the unaffected lower limb are longer in the gait cycle. This could mean that the affected lower limb is well compensated if the unaffected lower limb is strong enough; consequently, walking ability improves. Although assessments and interventions for hemiplegic stroke patients tend to focus on the affected lower limb, it is also necessary to evaluate and train the unaffected lower limb from an early stage.

\subsection{The Role of Spirituality}

Spirituality is found to influence walking ability as much as mental conditions, including motivation of walking training, which is enhanced by spirituality. Although the spirituality of patients with stroke has not been studied, spiritual care was reported to relieve wound pain after surgery in lung cancer patients [24]. In a previous study, it calmed a delirious critically ill patient [25]. Moreover, spirituality plays an important role in finding the meaning and purpose of life, especially when a person faces a life crisis [6] [7]. A person in a crisis utilizes spiritual coping strategies, arousing one's spirituality [26]. People with illness are in a crisis that can evoke their spirituality. Spiritual coping strategies are the processes through which patients overcome their pain by finding meaning and purpose in their illness. The use of spiritual coping strategies helps the patients empower themselves [26], and empowered patients may be highly motivated in rehabilitation training. Highly motivated patients view rehabilitation as the most important means of recovery and accord themselves an active role in rehabilitation [27]. Patients who actively engage in walking training may consequently improve their walking ability.

Spiritual coping strategies are facilitated and supported by spiritual care, which alleviates the spiritual pain of patients and includes active listening and sympathy [24]. The aforementioned case reports of a postsurgical lung cancer patient and a delirious critically ill patient demonstrate the effect of spiritual care. Since the two patients were facing a crisis in their lives, spirituality might have 
been enhanced by spiritual care. Patients with stroke also face a crisis due to the stroke onset and its neurologic manifestations; thus, spiritual care could potentially motivate these patients for walking training.

It is unknown whether the subjects received spiritual care; however, because of the association between FIM locomotion score and spirituality, it is possible that spirituality was enhanced in some way. If nurses understand the necessity of spiritual care and can introduce spiritual care from an early stage, they can enhance the spirituality of patients with stroke hemiplegia more quickly. This should lead to an accelerated improvement in walking ability.

\subsection{Other Variables}

No correlation was found between walking ability and age. Walking training should not be withheld based on the patient's age alone. In order to start walking training from an early stage, there is a need to assess not only age but also other factors and conditions. Furthermore, no correlation between walking ability and social support was observed. However, social support correlated with spirituality. Thus, since motivation of patients with stroke was enhanced by heightened spirituality, which consequently improved their walking ability, increased social support could also improve motivation and, thus, walking ability. Therefore, social support indirectly influences walking ability. It has been reported that a high level of social support from family members improves the functional status and mental health of patients with stroke [5]. A study may be necessary to investigate the association between spirituality and social support in the future. However, from this study, it is possible that social support indirectly affected walking ability. Therefore, efforts to improve social support, including family assistance, are also necessary.

\subsection{Implications for Clinical Practice}

The results of this study may be utilized in the assessment and intervention for hemiplegic stroke patients. Nursing practice implications are discussed below.

The assessment of walking ability in patients with stroke before the first attempt of walking training is necessary. Experiencing a fall at the first attempt of walking training may lead to a "fear of falling". During the assessment, the degree of motor paralysis and muscle strength of the unaffected lower limb and spirituality could help predict successful attempts. Measuring muscle strength through the lower limb loading force by a bathroom scale has been proven to be a useful method. A bathroom scale is inexpensive and readily available in any setting. Bedside nurses who are not trained for muscular strength measurement can easily measure the loading force. Further studies are needed to identify the critical value of the loading force in predicting the success of the first attempt of walking training.

Promoting walking ability in patients with stroke also includes training on the unaffected lower limb, which can be performed at the bedside or on the bed by the patient or a bedside nurse. To help patients quickly regain their walking abil- 
ity, nurses should encourage the patients to perform muscle strengthening exercises, such as straight leg raising training and quadriceps femoris muscle setting exercise, starting during the acute phase of recovery.

Heightening spirituality is apparently essential to improving walking ability in patients with stroke. One of the approaches to heighten spirituality is facilitating the patient's spiritual coping strategies through spiritual care, which includes active listening and sympathy, and nurses are capable of improving spirituality.

Active listening is defined as "encouraging someone to 'tell their story', checking that you are understanding their approach and meaning, and reassuring them that you are interested in what they are saying [28]". Patient care in the acute phase of recovery entails that nurses express interest in the patients' stories and understand their painful experiences, such as neurologic manifestations and motor paralysis.

Sympathy is defined as "a feeling of sorrow or anguish associated specifically with the suffering or need(s) of another; it can also be thought of as the act or capacity of entering into or sharing the feelings or interests of another [29]". Nurses who care for patients with stroke are expected to be sensitive to the patient's swaying emotions and to exchange affections with them to make them feel understood.

Furthermore, in this study, spirituality was correlated with social support and frequency of family visits; thus, increasing social support and the frequency of family visits may also heighten spirituality. Moreover, social support involves emotional support, which also includes active listening and sympathy [30]. Nurses who care for patients with stroke are encouraged to practice active listening and show sympathy as part of emotional support and spiritual care. Moreover, nurses should also encourage the patients' families to increase their visits.

\subsection{Limitations and Future Directions}

This study's generalizability is limited by the following: 1) the subjects had low stroke severity; thus, the findings may not be applicable to more severe stroke cases and 2) the subjects were all Japanese; from the differences in skeleton and culture, gait differences between Japanese and non-Japanese subjects might exist. There were no adverse events such as muscle injuries and falls due to the measurement of the lower limb loading force or mental burden due to the questionnaire.

Stroke treatment and brain lesions of stroke were not investigated. The types of stroke treatment, such as intravenous treatment or surgery, may have an effect on bed rest duration, and lesions may influence neuropsychological characteristics.

Future studies should include more severe cases in order to further investigate the factors influencing walking ability. Furthermore, interventional studies are necessary to explore the effectiveness of the interventions, including muscle training of the unaffected limb and spiritual care. 


\section{Conclusion}

This study investigated the factors affecting the walking ability of hemiplegic stroke patients. The result suggested that walking ability is influenced by the stroke severity and degree of paralysis, the unaffected lower limb loading force, and the level of spirituality.

\section{Acknowledgements}

I would like to express my deepest gratitude to Prof. Ikematsu Y. (Nagoya University) for the valuable comments and suggestions throughout the course of my study.

\section{Disclosures}

None.

\section{References}

[1] Maeda, M., Yorizumi, K. and Yokoyama, I. (1989) Factors Contributing to the Recovery of Outdoor Walking Ability in the Stroke Patients. The Japan Stroke Society, 11, 111-118. (In Japanese)

[2] Paul, S.L., Sturm, J.W., Dewey, H.M., Donnan, G.A, Macdonell, R.A. and Thrift, A.G. (2005) Long-Term Outcome in the North East Melbourne Stroke Incidence Study: Predictors of Quality of Life at 5 Years after Stroke. Stroke, 36, 2082-2086. https://doi.org/10.1161/01.STR.0000183621.32045.31

[3] Mochizuki, H. (2007) Impairments and Their Assessment in Stroke Patients. Rigakuryoho Kagaku, 22, 33-38. (In Japanese) https://doi.org/10.1589/rika.22.33

[4] Northcott, S., Moss, B, Harrison, K. and Hilari, K. (2016) A Systematic Review of the Impact of Stroke on Social Support and Social Networks: Associated Factors and Patterns of Change. Clinical Rehabilitation, 30, 811-831. https://doi.org/10.1177/0269215515602136

[5] Tsouna-Hadjis, E., Vemmos, K.N., Zakopoulos, N. and Stamatelopoulos, S. (2008) First-Stroke Recovery Process. The Role of Family Social Support. Archives of Physical Medicine and Rehabilitation, 81, 881-887. https://doi.org/10.1053/apmr.2000.4435

[6] Narayanasamy, A. (2004) The Puzzle of Spirituality for Nursing. A Guide to Practical Assessment. British Journal of Nursing, 13, 1140-1144. https://doi.org/10.12968/bjon.2004.13.19.16322

[7] Narayanasamy, A. (1999) A Review of Spirituality as Applied to Nursing. International Journal of Nursing Studies, 36, 117-125. https://doi.org/10.1016/S0020-7489(99)00007-3

[8] Bernhardt, J., Churilov, L., Ellery, F., Collier, J., Chamberlain, J., Langhorne, P., Lindley, R.I., Moodie, M., Dewey, H., Thrift, A.G. and Donnan, G. (2016) Prespecified Dose-Response Analysis for a Very Early Rehabilitation Trial (AVERT). Neurology, 86, 2138-2145. https://doi.org/10.1212/WNL.0000000000002459

[9] Tinetti, M.E. and Powell, L. (1993) Fear of Falling and Low Self-Efficacy: A Cause of Dependence in Elderly Persons. Journal of Gerontology, 48, 35-38. https://doi.org/10.1093/geronj/48.Special_Issue.35

[10] Akosile, C.O., Anukam, G.O., Johnson, O.E., Fabunmi, A.A., Okoye, E.C., Iheuk- 
wumere, N. and Akinwola, M.O. (2014) Fear of Falling and Quality of Life of Apparently-Healthy Elderly Individuals from a Nigerian Population. Journal of Cross-Cultural Gerontology, 29, 201-209.

https://doi.org/10.1007/s10823-014-9228-7

[11] Schmid, A.A., Arnold, S., Jones, V.A., Ritter, M.J., Sapp, S.A. and Van Puymbroeck, M. (2015) Fear of Falling in People with Chronic Stroke. American Journal of Occupational Therapy, 69, Article ID: 6903350020. https://doi.org/10.5014/ajot.2015.016253

[12] Polit, D.F. and Beck, C.T. (2012) Nursing Research: Generating and Assessing Evidence for Nursing Practice. 9th Edition, LWW, Philadelphia.

[13] Keith, R.A., Granger, C.V., Hamilton, B.B. and Sherwin, F.S. (1987) The Functional Independence Measure: A New Tool for Rehabilitation. Advances in Clinical Rehabilitation, 1, 6-18.

[14] Higa, H. (2002) Development of Spirituality Rating Scale and Study of Its Reliability and Validity. Japan Journal of Nursing Science, 22, 29-33. (In Japanese)

[15] Higa, H. (2006) The Evaluation Method of Spirituality. Journal of Clinical and EXperimental Medicine, 216, 163-167. (In Japanese)

[16] Iwasa, H., Yasuyuki, I., Masui, Y., Inagaki, H., Kawai, T., Otsuka, R., Ogawa, M., Takayama, M., Imuta, H. and Suzuki, T. (2007) Development of a Japanese Version of Multidimensional Scale of Perceived Social Support, and Examination of Its Validity and Reliability. Journal of Health and Welfare Statistics, 54, 26-33. (In Japanese)

[17] Muangman, P., Sullivan, S.R., Wiechman, S., Bauer, G., Honari, S., Heimbach, D.M., Engrav, L.H. and Gibran, N.S. (2005) Social Support Correlates with Survival in Patients with Massive Burn Injury. Journal of Burn Care and Rehabilitation, 26, 352-356. https://doi.org/10.1097/01.BCR.0000169894.37249.4D

[18] Brott, T., Adams, H.P., Olinger, C.P., Marler, J.R., Barsan, W.G., Biller, J., Spilker, J., Holleran, R., Eberle, R. and Hertzberg, V. (1989) Measurements of Acute Cerebral Infarction: A Clinical Examination Scale. Stroke, 20, 864-870. https://doi.org/10.1161/01.STR.20.7.864

[19] Brunnstrom, S. (1970) Movement Therapy in Hemiplegia: A Neurophysiological Approach. Medical Dept, Harper \& Row, New York.

[20] Murata, S. and Miyazaki, M. (2005) Assessment of Lower Extremities Function in Elderly People with Dysfunction-Measurement of Lower Limb Supporting Force with Scales-Measurement of Lower Limb Supporting Force with Scales. The Society of Physical Therapy Science, 20, 111-114. (In Japanese)

[21] Cho, K.H., Lee, J.Y., Lee, K.J. and Kang, E.K. (2014) Factors Related to Gait Function in Post-Stroke Patients. Journal of Physical Therapy Science, 26, 1941-1944.

[22] Bohannon, R.W. and Williams, A.A. (2011) Normal Walking Speed: A Descriptive Meta-Analysis. Physiotherapy, 97, 182-189. https://doi.org/10.1016/j.physio.2010.12.004

[23] Von Schroeder, H.P., Coutts, R.D., Lyden, P.D., Billings, E. and Nickel, V.L. (1995) Gait Parameters Following Stroke: A Practical Assessment. The Journal of Rehabilitation Research and Development, 32, 25-31.

[24] Murata, H. (2011) Spiritual Pain and Its Care in Patients with Terminal Cancer. Journal of Japan Society of Pain Clinicians, 18, 1-8. (In Japanese)

[25] Murata, H. (2014) Spiritual Care for the Critically-Ill Patients. Journal of Japan Academy of Critical Care Nursing, 10, 11-14. (In Japanese) 
[26] Baldacchino, D. and Draper, P. (2001) Spiritual Coping Strategies: A Review of the Nursing Research Literature. Journal of Advanced Nursing, 34, 833-841. https://doi.org/10.1046/j.1365-2648.2001.01814.x

[27] Maclean, N., Pound, P., Wolfe, C. and Rudd, A. (2000) Qualitative Analysis of Stroke Patients' Motivation for Rehabilitation. British Medical Journal, 321, 1051-1054. https://doi.org/10.1136/bmj.321.7268.1051

[28] Bryant, L. (2009) The Art of Active Listening. Practice Nurse, 37, 49-52. https://doi.org/10.1080/09540120600578409

[29] Norman, L.R., Carr, R. and Uche, C. (2006) The Role of Sympathy on Avoidance Intention toward Persons Living with HIV/AIDS in Jamaica. AIDS Care, 18, 1032-1039.

[30] Cohen, S. (2004) Social Relationships and Health. American Psychologist, 59, 676-684. https://doi.org/10.1037/0003-066X.59.8.676 